\title{
Aspects of Health Care Measures of New Born Among the Tai Phakes of Upper Assam, India
}

\author{
Arifur Zaman* \\ Department of Anthropology, Dibrugarh University, India
}

Submission: July 09, 2017; Published: July 28, 2017

*Corresponding author: Arifur Zaman, Department of Anthropology, Dibrugarh University, Assam, India, Email: arifurzaman@gmail.com

\begin{abstract}
Health care specially the health care of the child is one of the prime necessities of human society. In the tender years the child need extreme care and affection. Gradually when it grows up certain measures has to be adopted by the fellow members to make the child adjust with the social environment. Feeding practices, weaning, toilet training, bathing practices, sleeping, etc., are some of the criteria which are of utmost importance in upbringing of the child. In this present endeavour an attempt has been made to delineate about the early measures in relation with child care and upbringing among the Tai Phakes of Nam Phake village of Upper Assam, India.
\end{abstract}

Keywords: Child; Health care; Tai phake; Breast feeding; Weaning; Family planning

\section{Introduction}

Child care practices are embedded in the culture and determine, to a large extent, the behaviors and expectations surrounding a child's birth and infancy. While the mother remains the primary person responsible for the safety, care and feeding of the child, it is during the toddler period that the child moves out from the mother. Over time others in the family and community play an increasingly important role in the care of the child, particularly in terms of socializing and teaching the child through direct instruction and modeling. In the early years of an individual's life, it is largely a matter of conditioning to fundamentals - habit of eating, sleeping, speaking, personal cleanliness, etc. Tai Phake people give importance to respect and extend a good treatment to the mother. They consider mother as a social entity and offer all support for her safety, security and welfare. For Tai Phake people children are desirable for the continuation of lineage and for the satisfaction of the self. According to their beliefs children are the gift of God whether it is a boy or girl. Thus birth of child is considered useful for helping in economy, assisting parents and guardians and to carry out the generation.

Child bearing is an essential part in an adult women's life of Tai Phake people. Life without a child is unthinkable. Inability to conceive or to have a no living child usually a serious matter for them and such type of women was not treated positively among them in the earlier times. They had the belief that failure to conceive is women's fault only. Therefore whenever they found that a woman conceiving a child it brings joy to them. If some women fail to conceive a child then for getting a child, local herbal treatment for the women was generally prescribed. For the sake of a child, the Tai Phake couple usually visited to the Buddha Bihar and prayed to the almighty in several times. In early days the women generally felt shy to disclose their pregnancy though pregnancy is a matter of pride to the Tai Phake women. But when they found that the continuation of menstruation has stopped, and the women starts vomiting and feeling weak, then they become sure that the women has got pregnant. The pregnant women observes rigorous bodily concealment by putting her shin (a kind of lower garment encircling round the waist worn by the assamese women folk) and nangwat (a short top) nicely to cover her belly. The women consider that the pregnant lady should restrict her movement outside the boundary in order to rescue from the evil spirits. The pregnant lady is under care of the mother in law or other elderly member but for the sake of physical fitness she is not free from her usual domestic duties as well as agricultural work.

Elaborate ethnographic study of a particular community regarding the care of the newborn and the mother, customs, rituals, taboos, etc., related with pregnancy and birth were carried out by different scholars like [1-11] and they also focus on the correlation of beliefs and practices with birth and social life. In matter of discipline a Tai Phake child is always under the watchful eye of their mother, grandmother and other immediate 
members of the family. During early childhood limited attention alone is given for maintaining hygiene. According to their view, helping a child learn positive behaviours and values requires years of parental effort and teaching. Children do not naturally do all the things parents want to do. They said that children usually learn by imitating their parents, siblings and other members.

\section{Micro Field and People}

The Nam Phake village is situated about $5 \mathrm{~km}$ from Naharkatia town of Dibrugarh Distirct. In Nam Phake village there are 81 households and a population of 320. It is a homogenous village predominantly inhabited by the Tai Phakes. Dibrugarh District is one of the 32 districts of Assam, India. Situated in the eastern part of Assam, Dibrugarh stands high and tall with its rich aesthetic appeal. The main communities living in the district are Ahoms, Tea Garden Workers, Sonowal Kacharis, Mishings, Deoris, Tai communities like Tai Phakes, Tai Khamyang, etc.

The Tai Phakes are one of the scheduled tribes of Assam. They are Buddhist by religion. The origin of the Tai Phakes has been exhaustively dealt by different scholars. But uptill now only little is known about their origin and migration. The Tai Phake people were believed to have migrated from the Shan kingdom of Mong Mao (Muang Mao), Myanmar in the 18th century. They now became one of the distinctive ethnic groups inhabiting the plain areas of Dibrugarh and Tinsukia Districts of Upper Assam, India. The Tai Phake people speak Phake language among them and speak Assamese with the neighbouring ethnic groups and other people of the state. The Phake language is similar to those of Shan. They have their own separate scripts and also have preserved manuscripts. The main economy of the Tai Phakes is agriculture along with cattle and buffalo rearing.

\section{Objectives}

a) The present study tries to examine.

b) The patterns and measures of feeding and weaning practices associated with the child;

c) Role of the family members incorporated in toilet training of the child;

d) The measures taken by the parents and other members with regards to bathing practices, sleeping and so forth;

e) Traditional and modern health care measures available to the study area.

\section{Methodology}

The intended study is based on aspects integral to child care practices of the Nam Phake Village of Naharkatiya area of Dibrugarh District, Assam. The empirical data for the present study has been collected at regular interval during the month of January to April, 2017. In this present study data has been gathered from mothers who have at least one child within 4 years of age. The primary data for this study has been collected with the help of standard anthropological field methods viz., nonparticipant observation, structured and unstructured interview, concrete case study method, etc. With observation method, information regarding behavior patterns of children, their day to day activities and their interaction with fellow family members were recorded. Interview and case study methods were applied to collect empirical information about pristine methods of child care along with ways and means applied for toilet training, sleeping, bathing practices, weaning, personal hygiene / cleanliness and feeding of the child. The data gathered by one method/ one individual is cross checked by another method/ another individual as and when situation demands.

\section{Results and Discussion}

\section{Care during pregnancy}

During pregnancy Tai Phake women take care of her in all aspects that are in food habit, carrying out normal routine work, health care from the medical doctor, etc. The women generally prohibited food items like alkali (khar), sour foods, pepper, papaya, chilies, bitter food, pulse, jackfruit, egg, twin banana, as these food may cause abortion, anemia, indigestion, pains in abdomen, nausea. Jack fruit (malang) is prohibited because it makes the baby's skin rough and egg is also prohibited during pregnancy due to the believe that the baby becomes bald. Twin banana is also restricted because it leads to the birth of twin baby, though birth of the same is whole heartedly welcome in their society. Besides these Tai Phake women are prescribed to take milk or curd which enriches breast milk. Leafy green vegetables are also preferred with that the baby will have emmence growth of hair on head.

In case of daily routine work during pregnancy Tai Phake women carry out all the normal routine works which they able to do. Husbands and other members also shared their work like fetching water, washing clothes, sweeping and moping etc. During pregnancy women are restricted to do weaving. At present, all the women are aware about their health so they receive health care from medical doctor and take TT vaccine, iron and folic acid tablets and regular go for their health check up.

\section{Initiation of Breast Feeding}

Food is one of the major necessities for proper growth and nutrition of the child. Mother's milk is the nature's most precious gift to the neonate. The most essential and highly nutritious food for the newborn baby is the mother's milk. Breast feeding is not only important for the growth of the infant but also helps the enlarged uterus to contract easily and revert back to its normal position. Breast feeding is emotionally satisfying, bringing mother and child together (Table 1).

Table 1: Distribution of mothers according to time of initiation of breast feeding.

\begin{tabular}{|c|c|c|}
\hline Time of Initiation & No of Mothers & Total (\%) \\
\hline $\begin{array}{c}\text { Immediately after } \\
\text { birth }\end{array}$ & 48 & 80.00 \\
\hline Within 24 hours & 08 & 13.33 \\
\hline Between 24-48 hours & 04 & 6.67 \\
\hline Total & 60 & 100 \\
\hline
\end{tabular}


Ways of feeding also varies from community to community. Among the Tai Phakes, breast feeding is a common practice. Initiation of breast feeding mostly starts immediately after birth. Some reported that they initiated breast feeding within one hour due to less milk secretion in the initial stage. Mothers who delayed in breast feeding mentioned the reason that, they did not have milk soon after delivery. This may be due to the ignorance about the fact of early initiation of breast feeding stimulates milk secretion. There is generally no scheduled time for feeding. Most of the mothers were of the opinion that they fed their child whenever they cry and feels hungry. However, in the initial days they fed their baby in every 2 to 3 hours. Sometimes in order to increase breast milk, the parturient mother consumes black pepper, garlic, raw turmeric mixed with cow's milk once in a day. The Tai Phakes mostly rely on mother's milk atleast for the first 6 months of the new born baby. However, the common reason for stopping it is due to another pregnancy. The Tai Phakes stop breast feeding only when the mother comes with another pregnancy. Further reasons like less secretion of milk, baby's refusal to suckle breast milk, and so forth are not so common among the Tai Phakes.

\section{Pre-lacteal feeds}

The term pre-lacteal feed represents the food introduced to the baby before giving mother's milk. These pre-lacteal feeds are mostly given to the babies if mother's milk is delayed. But among Tai Phakes, it is also given even though breast feeding is not delayed. In such cases babies are provided with cow's milk until the mother's milk is initiated. During the first time, they provide cow's milk by diluting it with water, as it can make the baby's stomach upset. However, after initiating breast milk, they have never given any other foods except breast milk. They mostly use bowl and spoon to feed the baby. Use of feeding bottle is not so common among the people of those villages. It is further observed that the trend of breast feeding is quite impressive among the Tai Phakes. Apart from mother's milk, it is seen that they also provide honey and warm water for cleaning the mouth of the child and remove the sticky materials inside the baby's mouth, so that the newborn child would not face any difficulty in sucking the breast (Table 2).

Table 2: Distribution of mothers according to type of pre-lacteal feeds given to the newborn.

\begin{tabular}{|c|c|c|}
\hline Type of Food & No of Mothers & Total (\%) \\
\hline No food & 35 & 58.33 \\
\hline Cow's milk and water & 08 & 13.33 \\
\hline $\begin{array}{c}\text { Honey and warm } \\
\text { water }\end{array}$ & 17 & 28.34 \\
\hline Total & 60 & 100 \\
\hline
\end{tabular}

\section{Weaning}

Children in the Tai Phake families are normally fed on breast milk continuously upto 6 month and some of the women feed till 4 month after delivery. After that the weaning process starts. The period of breast feeding was shorter among those women who are able to replace breast milk with the cow's or tinned baby milk powder. Majority of the women reported that they feed their children on breast milk till two and half year to three years of age. The reason behind it is that they send their child to the play school which is situated at nearby Naharkatia town. Some of the women continued to breast fed their child till their next pregnancy. They also do supplementary feedings for the growth and development and also for nutritional purposes of the child which includes rice powder, cerelac, horlicks, milk, etc.

Weaning is an important event in the children's life. It is a process that refers to the manner in which the infant is departed or weaned from the mother's breast. The Tai Phake women believe that weaning cause great frustration and it has a traumatic effect. Weaning often results in emotional upset in children. Therefore the women become very conscious while weaning the child. It is reported that at first the mother introduces an alternative food to the child. Gradually they give other complementary food and at least some of the women put dried neem (Azadirachta indica) leaves making a paste and other bitter paste placed on to their nipple and gradually the child is departed from the mother's brest milk.

The Tai Phakes mostly answered that they do not use any specific measure to wean away their children. In such cases, children themselves gradually refuse to suckle mother's breast. The reason may be pregnancy of the mother or birth of the younger one. When the mother becomes pregnant again, their milk becomes watery and the babies are not fond of it and stops taking it. They informed that Neem leaves (Azadirachta indica), chili powder, etc., were applied in the nipple of the mother's breasts for the weaning of the child. The old ladies also said that they did not show bare breast to the children thereby avoiding any temptation for sucking and attention was diverted by providing weaning food. Apart from these materials like mud, black pepper and so forth are also applied to wean the child. One of the mother also reported that as her child scared of blood, she used red nail polish in the nipples which appears as blood so that the child gets scared and stops sucking milk. Among the people under study, weaning is a smooth and gradual process and does not possess any strict rule. Weaning, among them, takes place in a natural way so that it does not show any adverse effect in the personality formation of the children in due course of time (Table 3).

Table 3: Distribution of mothers according to time of

\begin{tabular}{|c|c|c|}
\hline Time of Weaning & No of Mothers & Total (\%) \\
\hline Between 4-6 months & 31 & 51.67 \\
\hline Between 6-9 months & 14 & 24.33 \\
\hline $\begin{array}{c}\text { Between 9-12 } \\
\text { months }\end{array}$ & 15 & 25.00 \\
\hline Total & 60 & 100 \\
\hline
\end{tabular}

Rice is the common practice in Tai Phakes, which is used as first solid food. In most of the cases, it is smashed with potato, leafy vegetables, diluted dal, etc. Cerelac is not so common food 
among them. Tai Phakes mothers mentioned of giving roasted rice flour and bhimkol (a variety of banana; Musa balbisinia) mixture. They even provide biscuit soaked either in milk or in hot water. They never add oil or ghee in their baby's food. They mostly prefer boiled foods. Feeding children from a separate utensil is a good practice among most of the Deori mothers $(72.27 \%)$, so that they can measure how much amount of food the baby has taken. Children are mostly fed by their mothers. The other family members also take part as well. Among the Tai Phakes, children are also encouraged to eat by their own.

Nearly 71.67 percent of the studied mothers followed scheduled pattern of complementary pattern of feeding and rest $(28.33 \%)$ mentioned of demand pattern. Mothers who provide solid food to their child along with breast milk followed scheduled feeding in respect of solids and demand pattern for mother's milk (Table 4, 5 \& 6).

Table 4: Distribution of mothers according to measures initiated to stop breast feeding.

\begin{tabular}{|c|c|c|}
\hline Measures Used & No of mothers & Total (\%) \\
\hline No measures & 29 & 48.33 \\
\hline $\begin{array}{c}\text { Use of bitter } \\
\text { substance }\end{array}$ & 17 & 28.33 \\
\hline Use of mud & 06 & 10.00 \\
\hline Use of black pepper & 07 & 11.67 \\
\hline Use of red nail polish & 1 & 1.67 \\
\hline Total & 60 & 100.00 \\
\hline
\end{tabular}

Table 5: Distribution of mothers according to type of complementary foods initiated.

\begin{tabular}{|c|c|c|}
\hline Type of Food & No of Mothers & Total (\%) \\
\hline Rice & 26 & 43.33 \\
\hline $\begin{array}{c}\text { Smashed potato and } \\
\text { leafy vegetable soup }\end{array}$ & 13 & 21.67 \\
\hline $\begin{array}{c}\text { Roasted rice flour } \\
\text { and bhimkol (Musa } \\
\text { balbisinia) }\end{array}$ & 10 & 16.67 \\
\hline $\begin{array}{c}\text { Biscuit soaked in } \\
\text { water or milk }\end{array}$ & 11 & 18.33 \\
\hline Total & 60 & 100 \\
\hline
\end{tabular}

Table 6: Distribution of mothers according to pattern of feeding of complementary food.

\begin{tabular}{|c|c|c|}
\hline Pattern of Feeding & No of Mothers & Total (\%) \\
\hline Scheduled pattern & 43 & 71.67 \\
\hline Demand pattern & 17 & 28.33 \\
\hline Total & 60 & 100 \\
\hline
\end{tabular}

\section{Toilet training}

The Tai Phake mother begins to care for toilet values of the infants after the birth of the child. In early days if the new born baby wets the clothes it was changed and body was cleaned with water. The mother of the baby immediately understands the signals of the children and leaves their work and washes them. When the child became three to four months old, mother stretches her legs and makes the child to sit and produce a kind of hissing sound. After that the infants are stimulated by the sound and urinate. When the child grows one or two years old the mother instructs him to go out of the home for urination or defecation. As there were no latrines in the early days so as the child become 3 to 4 years it was sent to the nearby barren places of the forest.

\section{Sleeping}

Sleeping is also a very necessary action for proper growth of a baby. It is equally important for the baby for proper rest. Tai Phakes mothers are also concerned for their baby's good and sound health. They reported that in the first three months the baby sleeps most of the times and gets up only at the time of feeding or when he is disturbed. As the age of the baby increases his sleeping tendency becomes less and less and he wakes up more frequently to play with his own hands and feet. They further said by the end of one year of age, the baby is gradually adjusted to two naps a day. They also highlighted that while putting the baby to sleep in a cradle, they make them sleep in both sides to give proper shape to the head. Among the Tai Phakes, the cradle should be completed in a day; otherwise the baby may suffer from restlessness and may cry. They further install a pillow made of mustard seeds for making the head of the newborn round in shape as and when it sleeps. The bed of the newborn should usually be soft, comfortable and clean. Most of the mothers reported the use of old cloths for making the bed for the baby by spreading the cloth on the same bed of the mother. Few mothers used quilt made with old cloths. Use of plastic sheets was also informed by some mothers. However, they maintain minimum cleanliness in connection with the baby's bedding.

\section{Bathing practices}

Bathing is very closely and intimately related to our culture and climate. There are variations seen regarding bathing practices among the Tai Phakes children.

However information regarding first bath of the child was collected from the cases of home deliveries. Majority of mothers use warm water for their child. In all the cases the birth attendants cleaned and bathed the newborns. Bathing also depends on season. During winter the mothers consider that regular bathing may make their child more prone to diseases. The materials used for bathing also vary from mother to mother. They use oil, soap, turmeric and so forth. Some informed the use of neem leaves and water to prevent the child from skin allergy. The newborn is usually wrapped up in a soft clean cloth immediately after birth. Such type of cloth is a clean piece of mother's chadar (a part of women's dress of the Tai Phakes) or a gamocha (hand-woven towel). The main reason of giving old, used, cotton cloth to the newborn is because of its cleanliness and hygiene. However, no any custom was found among them while providing the first piece of cloth to the neonate. It was informed in each of the Tai Phakes household there was an arrangement of fire in one corner of the room where the mother and the child 
was kept after bathing. They further sprinkled mustard seeds in that fire to keep the evil spirits away. They also tied red chilies on the beam of the door (Table 7).

Table 7: Distribution of mothers according to frequency of giving bath to their children.

\begin{tabular}{|c|c|c|}
\hline Frequency & No of Mothers & Total (\%) \\
\hline Daily & 17 & 28.33 \\
\hline Every alternate day & 07 & 11.67 \\
\hline $\begin{array}{c}\text { Whenever the } \\
\text { mother feels }\end{array}$ & 05 & 8.33 \\
\hline Twice in a week & 09 & 15.00 \\
\hline $\begin{array}{c}\text { Daily in summer } \\
\text { and alternate day in } \\
\text { winter }\end{array}$ & 22 & 36.67 \\
\hline Total & 60 & 100 \\
\hline
\end{tabular}

\section{Teething}

Teething is marked between sixth to eight months. However the first three years of a child's life is very important for his teeth. But the eruption depends on the health, heredity, nutrition before and after birth, diet of the mother during pregnancy, race, sex and other factors. Certain beliefs in respect of eruption of tooth do exist in all cultural groups, but among the Tai Phakes, it is found that in most of the cases the mothers are unaware of such belief. But some of the elderly women could explain that if the tooth first erupts in the upper jaw, then the child may become very intelligent and expert in climbing, whereas eruption of tooth in the lower jaw is considered as normal. Some of them belief, that for a boy eruption of tooth of upper jaw and for a girl, eruption of tooth in a lower jaw is good. Some babies even suffer from fever, cold and diarrhoea at the time of teething. It is due to sleeplessness during the teething process. This process of teething continues up to two and half to three years of age. They reported that these teeth are smaller in size and not so strong.

\section{Magico religions belief}

Soon after birth the Tai Phake people tied a piece of rhizome of the bos (Acorus calamus) with thread, either encircling the neck, wrist of hand or in feet, which is believe to be keep the child free from any type of evil spirit and bad eyes of human being. This is in practice at present also.

\section{Family planning}

There was practically no prevalence of traditional birth control measures or practices among the women of the Nam Phake village. They did not use any contraceptive measures. They were aware of the natural birth control measure and remain far from sexual intercourse when they do not want child. Coitus intereptus or withdrawal method is another pristine way to refrain a woman from conceives. Otherwise they gave more number of births as they have the belief that more number of children will be helpful for carrying out agricultural work and enhance their population. But at present the married couple aware about the family planning measures which they learn from the sources like newspaper, magazine, medical personal, internet, and so forth. Majority of the women adopted birth control measures by taking contraceptive and other measures from the doctor.

\section{Health care and assessment of nutritional status of children}

Traditionally, in Nam Phake village, majority of the mothers did not know anything about the immunization process. The child was not given any supplement, vitamins, growth tonic etc for his good health. But they were given to drink chicken soup so that the child becomes healthy. When the child gets sick the Tai Phake women treated by some herbal medicine. When child suffer from cold and cough they make a paste of ginger, turmeric and after that make a juice and mix it with honey, heat it and before going to the bed at night they gave it to the children. Sometimes they make tea with Tulsi (basil) leaves and allow their children to drink. When the children get wounded then the paste of turmeric is placed on the wounded position. If the children suffer from dysentery they provide lemon juice to drink and for fever the child is allowed to seat near the fire of hearths and then garlic seed and mustard oil is heated together and the bearable warm solution is applied into the hand, feet, back of the body of the child.

\section{Modern health care resources}

In the Tai Phake village three types of health resources are prevalent to the easy reach for the villagers. These are the ANM nurse of the primary sub health centre of the village, ASHA (Accredited Social Health Activist) worker and the Anganawadi (rural mother and child care activist) worker. This health activist counsel about the modern health care measures of mother and child care to the villagers. They provide information about the services of the mother which includes: T. T. vaccination, immunization, prevention and treatment of anemia, delivery by trained personnel, institutional delivery, and birth spacing. These again include the steps like - early registration of pregnancy, promotion of institutional deliveries, promotion of birth deliveries, provision of family planning, used of contraceptives, promotion of exclusive breast feeding for the first 4-6 months, proper weaning, infant immunization, improvement of maternal knowledge about home management, creation of awareness about essential real born care among the pregnant women and mothers of new born.

It is encouraging to note that all the children among the studied population had been immunized with all the necessary vaccines. In the village children are immunized previously in the primary health center and now a day's ASHA worker and Anganwadi worker takes initiative in this case. Nurses generally guides the villagers to the hospitals and on the next day nurses from the primary health centre or the ASHA worker and Anganwadi worker themselves visit the household and provide polio to the children from each and every household. 
The primary sub health centre of the village namely Namphake primary health centre is the only hospital situated in the village. The hospital was established in the year 1978. There is one ANM nurse and two helpers who help in taking care of the village people. They have the facilities such as weighing machine, machine to check blood pressure, hemoglobin, etc. Different types of patient such as those suffering from diarrhea, dysentery, fever, stomach pain, cold and cough come to the hospital. The nurse provides the first aid treatment to them and if they do not recover, then referred to nearby Naharkatia community health centre. In case of women specially the pregnant women they have the facilities to test the pregnancy, they do registration to all the women who is going to reproduce similarly they also test the blood pressure and hemoglobin percentage to the pregnant lady. The primary health centre gives all the basic facilities to the pregnant women such as TT vaccine, iron and folic acid etc. children are also given polio and all types of vaccines.

\section{Conclusion}

From the above discussion, it is found that, duration of breast feeding is quite impressive and most of the mothers fed their child for a longer duration. Time of introduction of solids food along with breast milk is satisfactory. Absence of food taboos is observed both for the mothers and their children. Nevertheless, it can be stated that although the mothers shows a positive figure in case of feeding practices of the child, personal cleanliness is still a matter of great concern among the Tai Phakes under study. Though traditionally, the village women were not aware the scientific knowledge of application of breast feeding within 12 hours of delivery and its advantages in child health. But now a day due to the availability of modern health care facilities all the women becomes conscious and feed their child immediately after birth as this milk contain colostrums. The parturient mothers also consume milk during pregnancy so that they can get strength and after delivery can provide sufficient milk to their child. Most of the women feed their child by a fixed schedule. Some of them follow demand schedule to feed their child when the child cries. Others follow mixed schedule to feed their child. They feed the child more than 10 times in a day before 6 months of the child. At night also they feed the child when they awake from sleeping and sometimes when the child cries. A mother with her first child is not always familiar with the whole process of feeding. In the study area, the women who delivered her child at the hospitals learnt more about the process of breast feeding from the nurses of the respective hospitals.

\section{References}

1. Arya SC (1972) Infant and Child Care. Vikas Publishing House Pvt. Ltd. New Delhi, India.

2. Bhargava YS (1987) Diet of pregnant mother, in Maternal and Child Health. Alfa Publishers and Distributors, Bikaner, India, pp. 67-74.

3. Engle P (1992) Care and Child Nutrition: Theme Paper for the International Nutrition Conference (ICN).

4. Hurlock EB (1970) Child Growth and Development. McGraw-Hill Book Company, New York, USA.

5. Mcneal C, Amato RP (1998) Parents' marital violence, long-term consequences for children. Journal of Family Issues 19(2): 123-139.

6. Mead M (1963) The Coming of Age in Samoa. Penguin Books, New York, USA.

7. Medhi Birinchi K (1980) Beliefs, rituals and ceremonies connected with principal events of the life of the Pati Rabhas of Assam. The Bulletin of the Department of Anthropology, Dibrugarh University 1: 40-53.

8. Park K (2000) Preventive medicine in obstetrics, pediatrics, and geriatrics, in Textbook of Social and Preventive Medicine $\left(16^{\text {th }} \mathrm{edn}\right)$, Bhanot Publisher, Jabalpur, India.

9. Pool R (1986) Belief concerning the avoidance of food during pregnancy and immediate post-partum period in a tribal area of rural Gujarat, India. The Eastern Anthropologist 39(3): 251-257.

10. Zaman A (2011) A study on birth and associated aspects among the Tengapania Deoris in a village of Upper Assam. Bulletin of the Department of Anthropology, Gauhati University, India, 12: 56-66.

11. Zaman A (2012) Initiations of life: Dimensions of birth in a tribal community of Assam. The Asian Man 6(1): 39-45.

\section{Your next submission with Juniper Publishers} will reach you the below assets

- Quality Editorial service

- Swift Peer Review

- Reprints availability

- E-prints Service

- Manuscript Podcast for convenient understanding

- Global attainment for your research

- Manuscript accessibility in different formats

( Pdf, E-pub, Full Text, Audio)

- Unceasing customer service

Track the below URL for one-step submission https://juniperpublishers.com/online-submission.php 